\section{Category}

Organo- and

Biocatalysis

\section{Key words}

thioureas

cyanation

ketimines

\title{
Thiourea-Catalyzed Asymmetric Cyanation of N-Boc Ketimines
}<smiles></smiles>

$+\mathrm{TMSCN}$ (2.0 equiv)

$\mathrm{R}=\mathrm{Me}, \mathrm{Bn}$<smiles>CCC=Cc1ccc(Cl)c(Cl)c1</smiles>

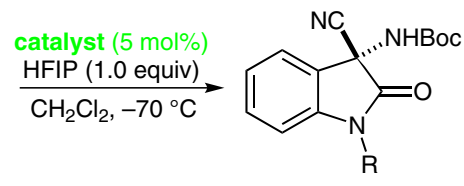

19 examples $65-95 \%$ yield er from 95:5 to $>99.5: 0.5$

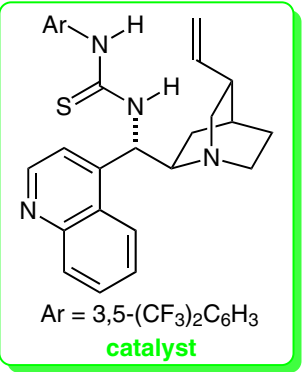

Application to the total synthesis of spirohydantoin I:<smiles>CC(C)(C)OC(=O)N[PH2+]C(=O)c1ccc(/C=C/CN2C(=O)C(=O)c3ccccc32)cc1Cl</smiles>

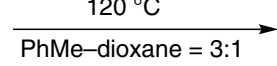<smiles>CCN1C(=O)C2(NC(=O)NC2=O)c2ccccc21</smiles>



spirohydantoin $34 \%$ yield er $=89.5: 10.5$

(er $=99.5: 0.5$ after one recrystallization)

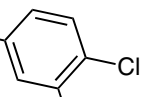

3 steps
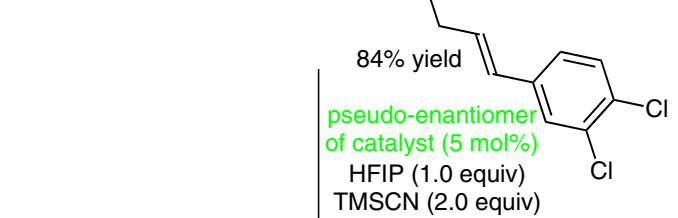

equiv)

$\checkmark$

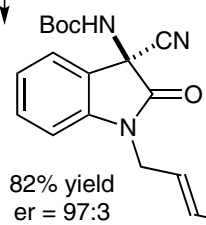

Significance: The first catalytic asymmetric cyanation of isatin-derived $N$-Boc ketimines has been reported by Zhou and co-worker. Wide substrate scope and excellent enantioselectivities were obtained. A tandem aza-Wittig-Strecker reaction has also been reported, which was applied to the total synthesis of spirohydantoin I.
Comment: An aza-Wittig-Strecker reaction sequence has been reported, which offers a good methodology to develop a catalytic asymmetric reaction of $\mathrm{N}$-Boc ketimines, generated in situ from the achiral ketones. The strategy has potential applications in other types of reactions, in which $\mathrm{N}$-Boc imines are involved. 